\title{
Effect of Gamma Irradiation on Aflatoxins and Ochratoxin A Reduction in Almond Samples
}

\author{
Di Stefano Vita ${ }^{1}$, Pitonzo Rosa ${ }^{2} \&$ Avellone Giuseppe ${ }^{1}$ \\ ${ }^{1}$ Dipartimento di Scienze e Tecnologie Biologiche, Chimiche e Farmaceutiche (STEBICEF), University of \\ Palermo, Italy \\ ${ }^{2}$ Centro Grandi Apparecchiature (CGA), University of Palermo, Italy \\ Correspondence: Di Stefano Vita, Dipartimento di Scienze e Tecnologie Biologiche, Chimiche e Farmaceutiche \\ (STEBICEF), University of Palermo, Via Archirafi 32, 90123 Palermo, Italy. Tel: 39-0912-389-1948. E-mail: \\ vita.distefano@unipa.it
}

Received: June 10, 2013 Accepted: December 10, 2013 Online Published: May 7, 2014

doi:10.5539/jfr.v3n4p113 URL: http://dx.doi.org/10.5539/jfr.v3n4p113

\begin{abstract}
The widespread contamination of food by mycotoxins may present a serious hazard to human and animal health. The gamma rays were applied to reduce ochratoxin $A$ (OTA) and aflatoxins $B_{1}, B_{2}, G_{1}$ and $G_{2}\left(A_{F} B_{1}, A_{F}\right.$, $\mathrm{AFG}_{1}$ and $\mathrm{AFG}_{2}$ ) in almonds artificially contaminated. In the present study we investigated the effect of gamma irradiation dosages, ranging from 0 to $15 \mathrm{kGy}$ and the reduction of mycotoxins concentration in almond samples. In order to determine the efficiency of the method, a high-performance liquid chromatography method with fluorescence detection was used, the mycotoxins were extracted from almond samples and then purified with immunoaffinity columns. The maximum reduction was found at $15 \mathrm{kGy}$ and it was $19.25 \%, 10.99 \%, 21.11 \%$, $16.62 \%, 23.90 \%$ for $\mathrm{AFB}_{1}, \mathrm{AFB}_{2}, \mathrm{AFG}_{1}, \mathrm{AFG}_{2}$ and $\mathrm{OTA}$ respectively. Results showed that gamma radiations even at $15 \mathrm{kGy}$, were not effective in completely destroying aflatoxins and ochratoxin $\mathrm{A}$.
\end{abstract}

Keywords: gamma ray, aflatoxins, ochratoxin A, almond, decontamination

\section{Introduction}

A wide range of commodities can be contaminated with mycotoxins both pre- and post-harvest. Aflatoxins (AFs) are the most prominent group of mycotoxins. The major aflatoxins are called aflatoxin $\mathrm{B}_{1}$, aflatoxin $\mathrm{B}_{2}$, aflatoxin $\mathrm{G}_{1}$ and aflatoxin $\mathrm{G}_{2}\left(\mathrm{AFB}_{1}, \mathrm{AFB}_{2}, \mathrm{AFG}_{1}\right.$ and $\left.\mathrm{AFG}_{2}\right)$. Aflatoxins are produced by a polyketide pathway by many strains of Aspergillus flavus and Aspergillus parasiticus as secondary metabolites (Yu et al., 2008).

The diseases caused by aflatoxin consumption are loosely called aflatoxicoses. Aflatoxins have been extensively studied with respect to their mechanisms of action, including their mutagenic and carcinogenic activity in human and animal populations. Recent studies demonstrated strong, significant positive correlations between estimated aflatoxin intake or aflatoxin levels in food samples and the incidence of liver cancer. (Report on Carcinogens, Twelfth Edition 2011).

The International Agency for Research on Cancer (IARC) has produced sufficient evidence in humans for the carcinogenicity of naturally occurring aflatoxins (IARC, 1987). This conclusion was reaffirmed in two subsequent reevaluations (IARC, 1993, 2002). The IARC has posted aflatoxin $\mathrm{B}_{1}$ on the list of probable human carcinogens (Jaimez et al., 2000).

Ochratoxin A (OTA) is another naturally occurring mycotoxin produced by Aspergillus ochraceus and Penicillium verrucosum (Meri, Marika, \& Aldo, 2005) The biological effects of OTA are well documented. There have been reports on its immunosuppressive nature, teratogenic, fertility inhibition, mutagenic and carcinogenic effects. OTA has been considered as the major agent responsible for the Balkan endemic nephropathy in humans. (Kuiper-Goodman \& Scott, 1989). Ochratoxin A it was classified by the IARC as a possible human carcinogen (group 2B) (IARC, 1993).

Efforts to reduce human and animal exposure to mycotoxins have resulted in the establishment of regulatory limits and monitoring program worldwide. Aflatoxins and OTA maximum limits have been established in the EU and other countries in the world. 
As a result of the high toxicity of aflatoxins and OTA, many methods have been used to reduce or eliminate them from different foods. The best way to reduce the mycotoxin content in food and feed is the prevention of mycotoxin formation in the field, but this is often not sufficient, so other methods are needed.

Physical, chemical or biological treatments of contaminated food and feed have poor efficacies and are not economically viable. Organic and inorganic adsorbents could be used to decrease the deleterious effects of contaminated foods, but many of them are banned for their adverse impact on human health and on the environment (UNEP, 1992; Loaharanu, 1998).

Researches carried out world-wide in the past four decades have shown that ionizing radiation processing could be an effective alternative to chemical treatment of foods to reduce fungal spore contamination of seeds, food or feeds or to degrade mycotoxins already produced (Gupta, 2001).

Treatment with ionizing radiation is considered as an effective physical method for the food preservation (Dhanya, Mishra, Khaleel, \& Cheruth, 2009), disinfestation, inhibition of sprouting, delay of fruit ripening, pasteurization and sterilization (Sánchez-Bel, Egea, Romojaro, \& Martìnez-Madrid, 2008; Chauhan, Kumar, Nadanasabapathy, \& Bawa, 2009; Waje et al., 2009; Sabato et al., 2009) and may be used to prolong shelf life of agricultural products (Queirol et al.,2002).

Conflicting data exist on the effectiveness of gamma radiation on the elimination/destruction of mycotoxins from food matrices. Some researchers reported a significant reduction and in many cases the complete elimination of mycotoxins in various foods; (Jalili, Jinap, \& Noranizan, 2010; Herzallah, Alshawabkeh, \& AL Fataftah, 2008; Prado et al., 2003; Jalili, Jinap, \& Noranizan, 2012); other data, instead, are in complete disagreement with these (Hooshmand \& Klopenstein, 1995; Feuell, 1966).

In the current study, we investigated the effect of gamma irradiation dosages, in the dose range of $0.5-15 \mathrm{kGy}$, on the reduction of $\mathrm{AFB}_{1}, \mathrm{AFB}_{2}, \mathrm{AFG}_{1}, \mathrm{AFG}_{2}$ and $\mathrm{OTA}$ in raw unpeeled almond kernels (Prunus dulcis).

\section{Reagents}

$\mathrm{AFB}_{1}, \mathrm{AFB}_{2}, \mathrm{AFG}_{1}, \mathrm{AFG}_{2}$ and OTA standards were purchased from Sigma-Aldrich Co (St. Louis, MO, USA). Syringe Filters was from Merck (Millipore; Milford, MA, USA); the $\mathrm{C}_{18}$ Luna HPLC column and security guard cartridge $\mathrm{C}_{18}$ were from Phenomenex (Torrance, CA, USA). The Aflaprep and Ochraprep immunoaffinity columns were obtained from r-Biopharm Rhône Diagnostic Technologies Ltd. (Glasgow, UK). All reagents used us hexane, acetic acid, trifluoroacetic acid were of analytical grade while HPLC solvents were of HPLC grade and were purchased from Carlo Erba (Milan, Italy).

\section{Method}

\subsection{Sample Collection}

Shelled almonds (Prunus dulcis (Mill.) D.A. Webb) variety Tuono were collected at the end of August 2011 in a local farm located in Naro, Agrigento (Sicily). Unpeeled almond kernels were obtained from shells by hand-processing and dried fruits were transferred to laboratory in polypropylene bags under cool conditions.

\subsection{Sample Preparation}

To investigate the effect of gamma doses on mycotoxins reduction, 30 almond samples (5 $\mathrm{g}$ each) were crushed, crumbled, pounded in a mortar, spiked with $\mathrm{AFB}_{1}, \mathrm{AFB}_{2}, \mathrm{AFG}_{1}, \mathrm{AFG}_{2}$ and $\mathrm{OTA}$ at $20 \mathrm{ng} / \mathrm{g}$, packaged in polyethylene bags and irradiated in the dose range of $0.5-15 \mathrm{kGy}$.

\subsection{Irradiation}

Irradiation of the almond samples, (5 g each, packaged in polyethylene bags) with gamma rays was carried out at the ISOF-CNR Bologna, in the ${ }^{60} \mathrm{Co}$ Nordion Gammacell 220, having a dose rate of about $7.5 \mathrm{~Gy} / \mathrm{min}$; irradiation chamber temperature during irradiation was $25^{\circ} \mathrm{C}$. The bags containing the almond samples were enclosed in a plastic chamber with wall thickness of $0.4 \mathrm{~g} / \mathrm{cm}^{2}$ which is suitable for establishing electronic equilibrium. The dose rate of the Gammacell for the reference geometry was determined with the alanine reference transfer standard dosimeters from RIS $\varnothing$ high dose reference laboratory, with an expanded uncertainty of $2.8 \%$ at $95 \%$ confidence level. The applied doses were $0.5,1.5,3,5,10$, and $15 \mathrm{kGy}$. The non irradiated samples were kept separated as control lots. All samples were stored at $-4{ }^{\circ} \mathrm{C}$ until further analysis.

\subsection{Mycotoxin Analysis}

A sample of almonds $(5 \mathrm{~g})$ was mixed with $20 \mathrm{~mL}$ methanol/water $(80: 20 \mathrm{v} / \mathrm{v})$ and shaken well for $10 \mathrm{~min}$. After filtration an aliquot of $5 \mathrm{~mL}$ was used for aflatoxin analysis and another one of $5 \mathrm{~mL}$ was used for OTA analysis. 


\subsubsection{Aflatoxins Determination}

Aflatoxin analysis were conducted with HPLC according to AOAC Official Methods with immunoaffinity column clean-up and fluorescence detection (AOAC, 1995).

$5 \mathrm{~mL}$ from the filtrate were diluted with $40 \mathrm{~mL}$ PBS and mixed for $1 \mathrm{~min}$. Mixture was loaded onto the Aflaprep (flow rate $2 \mathrm{~mL} / \mathrm{min}$ ) and washed once with $20 \mathrm{~mL}$ of deionized water. The column was then allowed to dry by passing air through it. $\mathrm{AFB}_{1}, \mathrm{AFB}_{2}, \mathrm{AFG}_{1}, \mathrm{AFG}_{2}$ were carefully eluted with $3 \mathrm{~mL}$ of acetonitrile. The eluate was then evaporated to dryness under a gentle stream of nitrogen and aflatoxin derivatives were obtained by adding $400 \mu \mathrm{L}$ hexane and $100 \mu \mathrm{L}$ trifluoroacetic acid. Then, $2 \mathrm{~mL}$ of a solution of deionized water/acetonitrile $(9: 1, \mathrm{v} / \mathrm{v})$ were added and vortex for $30 \mathrm{sec}$. to allow layers to separate. Aqueous layer containing aflatoxins was filtered through a $0.45 \mu \mathrm{m}$ syringe filter tip and analyzing by HPLC/FLD.

\subsubsection{Ochratoxin A (OTA) Determination}

Ochratoxin A was determined according to the methodology described by Villa and Markaki (2009).

$5 \mathrm{~mL}$ from the filtrate were diluted with $40 \mathrm{~mL}$ PBS and mixed for $1 \mathrm{~min}$. The mixture was loaded onto the Ochraprep immunoaffinity column (flow rate $2 \mathrm{~mL} / \mathrm{min}$ ) and washed once with $20 \mathrm{~mL}$ of deionized water. The column was then allowed to dry by passing air through it. OTA was carefully eluted with $3 \mathrm{~mL}$ of a solution of methanol/acetic acid $(98: 2, \mathrm{v} / \mathrm{v})$. The eluate was then evaporated to dryness under a gentle stream of nitrogen. The residue was dissolved immediately in $1 \mathrm{~mL}$ water/acetonitrile/ acetic acid (60:40:2), filtered through a 0.45 $\mu \mathrm{m}$ syringe filter tip and analyzing by HPLC/FLD.

\subsubsection{HPLC Analysis}

Reversed phase HPLC with fluorescence detection was used to determine $\mathrm{AFB}_{1}, \mathrm{AFB}_{2}, \mathrm{AFG}_{1}, \mathrm{AFG}_{2}$ and $\mathrm{OTA}$. The instrumentation was an Agilent 1100 Series liquid chromatograph included a binary pump (Model G1312A; Agilent, Agilent Technologies; Hewlett- Packard, Waldbronn, Germany), a fluorescence detector (Model G1312A; Agilent), a Rheodyne 7125 injection valve fitted with a $20 \mu$ loop and a column temperature controller (Thermosphere TS-130; Phenomenex, Torrance, California). Separation was achieved using a $\mathrm{C}_{18} 5 \mu \mathrm{m}$ particle size column (Luna C18 (2) 100A, $150 \times 4.6 \mathrm{~mm}$ ), equipped with a security guard cartridge $\mathrm{C}_{18}(4 \times 3.0 \mathrm{~mm})$ which was maintained at $40{ }^{\circ} \mathrm{C}$. The mobile phase consisted of water/acetonitrile (70:30) for aflatoxins and water/acetonitrile/acetic acid (60:40:2) for OTA. The mobile phase for AFs was filtered through Millipore filters $(0.45 \mu \mathrm{m})$ before use, as well as the mobile phase for OTA. The detection of $\mathrm{AFB}_{1}, \mathrm{AFB}_{2}, \mathrm{AFG}_{1}, \mathrm{AFG}_{2}$ was carried out at $\lambda_{\mathrm{ex}} 360 \mathrm{~nm}$ and $\lambda_{\mathrm{em}} 440 \mathrm{~nm}$. The detection of OTA was carried out at $\lambda_{\mathrm{ex}} 335 \mathrm{~nm}$ and $\lambda_{\mathrm{em}} 465 \mathrm{~nm}$. The flow rate was $1 \mathrm{~mL} / \mathrm{min}$ and the retention times were $3.1 \mathrm{~min}$ for $\mathrm{AFG}_{1}, 6.1 \mathrm{~min}$ for $\mathrm{AFG}_{2}, 3.6 \mathrm{~min}$ for $\mathrm{AFB}_{1}$, 7,7 min for $\mathrm{AFB}_{2}$ and $18.2 \mathrm{~min}$ for OTA (Figure 1).

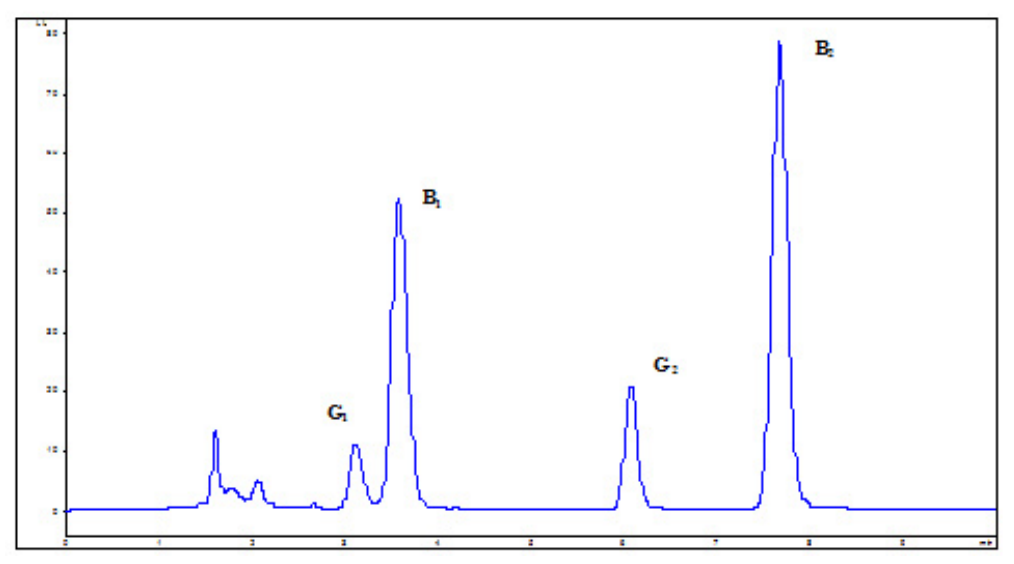

Figure 1. HPLC chromatogram obtained for detection of $\mathrm{AFB}_{1}, \mathrm{~B}_{2}, \mathrm{G}_{1}$ and $\mathrm{G}_{2}$ spiked into almond sample at level of $20 \mathrm{ng} / \mathrm{g}$ for all 


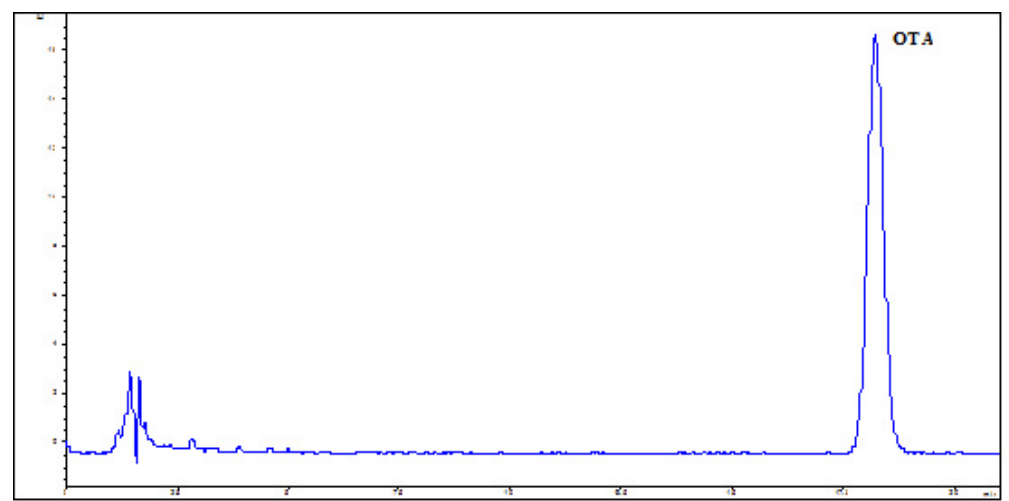

Figure 2. HPLC chromatogram obtained for detection of OTA spiked into almond sample at level of $20 \mathrm{ng} / \mathrm{g}$

\subsubsection{Preparation of Phosphate-Buffered Saline}

Phosphate-buffered saline (PBS) was prepared by dissolving $0.2 \mathrm{~g}$ potassium chloride, $0.2 \mathrm{~g}$ potassium dihydrogen phosphate, 2.92 anhydrous disodium hydrogen phosphate and $8.0 \mathrm{~g}$ of sodium chloride in $900 \mathrm{~mL}$ of distilled water. After adjusting the $\mathrm{pH}$ to 7.4 using $0.1 \mathrm{M} \mathrm{HCl} / 0.1 \mathrm{M} \mathrm{NaOH}$ if necessary, the solution was made up to $1000 \mathrm{~mL}$.

\subsubsection{Calibration Curve}

Working standard solutions were prepared daily by diluting the stock standard solutions in acetonitrile and stored at $-4{ }^{\circ} \mathrm{C}$ in amber colored glass bottles to protect them from direct light exposure.

To assess the possible effects of endogenous components in the food items, matrix-matched calibration was used for the quantification.

Five concentrations of matrix matched calibration $(4,8,15,20$ and $25 \mu \mathrm{g} / \mathrm{Kg})$ were prepared by spiking to the extract of blank almond sample with appropriate amounts of $\mathrm{AFB}_{1}, \mathrm{AFB}_{2}, \mathrm{AFG}_{1}, \mathrm{AFG}_{2}$ and $\mathrm{OTA}$ working solutions, and following the clean-up and derivatization procedure.

The results show that the standard calibration graphs were linear over the same range for $\mathrm{AFB}_{1}, \mathrm{AFB}_{2}, \mathrm{AFG}_{1}$, $\mathrm{AFG}_{2}$ and OTA (4.0-25.0 ng/mL), correlation coefficients $\left(\mathrm{r}^{2}\right) 0.998$ for all mycotoxins. Limit of Quantitation (LOQ) values were found to be in the range $0.83-1.10 \mathrm{ng} / \mathrm{mL}$; Limit of Detection (LOD) values were found to be in the range $2.70-3.60 \mathrm{ng} / \mathrm{mL}$.

Three replications were carried out for each concentration. Each aflatoxin and OTA peak in the chromatogram was identified by comparing retention times with those of corresponding reference standard. The quantity of aflatoxin and OTA in eluate injected was determined by the respective standard curve of $\mathrm{AFB}_{1}, \mathrm{AFB}_{2}, \mathrm{AFG}_{1}$, $\mathrm{AFG}_{2}$ and OTA.

\subsubsection{Statistical Analysis}

Analysis of variances (ANOVA) was used to investigate the significant effects of gamma doses on the reduction of mycotoxins in almond samples. Comparison of the means was conducted using ANOVA with Post Hoc Turkey's test at $\mathrm{p}<0.05$.

\section{Results and Discussion}

The data represented in Table 1 show the effect of gamma ray doses $(5,10$, and $15 \mathrm{kGy})$ on the per cent reduction of $\mathrm{AFB}_{1}, \mathrm{AFB}_{2}, \mathrm{AFG}_{1}, \mathrm{AFG}_{2}$ and $\mathrm{OTA}$ in almond samples. The samples irradiated at $0.5,1.5$ and 3 $\mathrm{kGy}$, showed no significantly reduction. The effect of gamma irradiation dose on mycotoxins reduction was significant by increasing gamma ray dose from 10 to $15 \mathrm{kGy}$. In our results, the greatest per cent reduction was obtained by irradiation at $15 \mathrm{kGy}$, which ranged from $10.99 \pm 0.25$ to $23.90 \pm 0.80$ for aflatoxins and ochratoxin A.

The minimal reduction of the content of AFs and OTA is probably due to the absence of water in the samples irradiated.

Water appears to have an important effect on the reduction of AFs and OTA by gamma radiation. In fact, radiolysis of water produces free radicals that could react with mycotoxins (Jalili, Jinap, \& Noranizan, 2012). 
The addition of free radicals to double bonds, especially to those in aromatic or heterocyclic rings of mycotoxins, is an energetically positive reaction that can be considered responsible to reduction of $\mathrm{AFB}_{1}$ and $\mathrm{AFG}_{1}$ levels.

Table 1. Per cent reduction on aflatoxins and ochratoxin A (ng/g) in almond samples

\begin{tabular}{ccccc}
\hline Mycotoxin & \multicolumn{3}{c}{ Reduction \% (Mean \pm SD) } \\
\hline & control & $5 \mathrm{kGy}$ & $10 \mathrm{kGy}$ & $15 \mathrm{kGy}$ \\
$\mathbf{A F B}_{\mathbf{1}}$ & $0.03 \pm 0.09$ & $0.25 \pm 0.04$ & $12.87 \pm 0.66$ & $19.25 \pm 0.17$ \\
$\mathbf{A F B}_{2}$ & $0.04 \pm 0.07$ & $0.69 \pm 0.11$ & $2.98 \pm 0.34$ & $10.99 \pm 0.25$ \\
$\mathbf{A F G}_{\mathbf{1}}$ & $0.14 \pm 0.23$ & $4.15 \pm 1.29$ & $18.95 \pm 1.13$ & $21.11 \pm 1.96$ \\
$\mathbf{A F G}_{\mathbf{2}}$ & $0.25 \pm 0.21$ & $3.36 \pm 0.31$ & $10.04 \pm 0.94$ & $16.62 \pm 0.68$ \\
$\mathbf{\text { OTA }}$ & $0.11 \pm 0.09$ & $1.68 \pm 0.71$ & $16.34 \pm 0.22$ & $23.90 \pm 0.80$ \\
\hline
\end{tabular}

\section{Conclusion}

The effects of gamma irradiation ranging from 0.5 and $15 \mathrm{kGy}$ on the percent reduction of the mycotoxins $\mathrm{AFB}_{1}$, $\mathrm{AFB}_{2}, \mathrm{AFG}_{1}, \mathrm{AFG}_{2}$ and OTA in almond samples were investigated. The results showed that $15 \mathrm{kGy}$ dose was not sufficient to completely destroy the AFs and OTA.

Unfortunately it is not possible to increase the dose of ionizing radiations since the FAO/IAEA/WHO Expert Committee on Food Irradiation concluded already in its report of 1981 that "the irradiation of any food commodity up to an overall average dose of $10 \mathrm{kGy}$ presents no toxicological hazard, hence, toxicological testing of food so treated no longer required."

It is therefore concluded that the decontamination of mycotoxins by irradiation is necessary prior to their production from moulds.

\section{References}

AOAC Method 990.33, Official Methods of Analysis, 16th Ed. (1995).

Chauhan, S. K., Kumar, R., Nadanasabapathy, S., \& Bawa, A. S. (2009). Detection methods for irradiated foods. Compr. Rev. Food Sci. F., 8(1), 4-16.

Dhanya, R., Mishra, B. B., Khaleel, K. M., \& Cheruth, A. J. (2009). Shelf life extension of fresh turmeric (Curcumal onga L.) using gamma radiation. Rad. Phys. Chem., 78, 791-795. http://dx.doi.org/10.1016/j.radphyschem.2009.05.011

Farag, R. S., Rashed M. M., Hussein A. A., \& Abo-Hagar A. (1995). Effect of gamma radiation on the infected yellow corn and peanuts by Aspergillus flavus. Chem. Mikrobiol. Technol. Lebensm., 17, 93-98.

Feuell, A. J. (1966). Aflatoxin in groundnuts. Problems of detoxification. Trop. Sci., 8, 61-70.

Gupta, S. C. (2001). Irradiation as an alternative treatment to methyl bromide for insect control. FAO/IAEA/WHO, Vienna, Austria.

Herzallah, S., Alshawabkeh, K., \& AL Fataftah, A. (2008). Aflatoxin Decontamination of Artificially Contaminated Feeds by Sunlight, $\gamma$-Radiation, and Microwave Heating, Poultry Science Association. $J$. Appl. Poultry Res., 17, 515-521. http://dx.doi.org/10.3382/japr.2007-00107

Hooshmand, H., \& Klopenstein, C. F. (1995). Effects of gamma irradiation on mycotoxin disappearance and amino acid contents of corn, wheat, and soybeans with different moisture contents. Plant Foods Hum. Nutr., 47, 227-238. http://dx.doi.org/10.1007/BF01088331

IARC. (1987). Aflatoxins. In Overall Evaluations of Carcinogenicity. IARC Monographs on the Evaluation of Carcinogenic Risk of Chemicals to Humans, suppl. 7. Lyon, France: International Agency for Research on Cancer. pp. 83-87.

IARC. (1993). Aflatoxins. In Some Naturally Occurring Substances: Food Items and Constituents, Heterocyclic Aromatic Amines, and Mycotoxins. IARC Monographs on the Evaluation of Carcinogenic Risk of Chemicals to Humans, vol. 56. Lyon, France: International Agency for Research on Cancer. pp. 245-395.

IARC. (2002). Aflatoxins. In Traditional Herbal Medicines, Some Mycotoxins, Naphthalene and Styrene. IARC 
Monographs on the Evaluation of Carcinogenic Risks to Humans, vol. 82. Lyon, France: International Agency for Research on Cancer. pp. 171-366.

Jaimez, J., Fente, C. A., Vazquez, B. I., Franco, C. M., Cepeda, A., \& Mahuzier, G. (2000). Application of the assay of aflatoxins by liquid chromatography with fluorescence detection in food analysis. J. Chromatogr. A, 882, 1-10. http://dx.doi.org/10.1016/S0021-9673(00)00212-0

Jalili, M., Jinap, S., \& Noranizan, A. (2010). Effect of gamma radiation on reduction of mycotoxins in black pepper. Food Control, 21, 1388-1393. http://dx.doi.org/10.1016/j.foodcont.2010.04.012

Jalili, M., Jinap, S., \& Noranizan, M. A. (2012). Aflatoxins and ochratoxin a reduction in black and white pepper by gamma radiation. Rad. Phys. Chem., 81, 1786-1788. http://dx.doi.org/10.1016/j.radphyschem.2012.06.001

Kuiper-Goodman, T., \& Scott, P. M. (1989). Risk assessment of the mycotoxin ochratoxin A. Biomed. Environ. Sci., 2, 239-248.

Loaharanu, P. (1998). International developments of food irradiation. Washington, DC, USA. FAO/IAEA, Vienna, Austria.

Meri, K., Marika, J., \& Aldo, R. (2005). The effect of substrate on mycotoxin production of selected Penicillium strains. Int. J. Food Microbiol., 99, 207-214. http://dx.doi.org/10.1016/j.ijfoodmicro.2004.08.014

Prado, G., Carvalho, E. P. D., Oliveira, M. S., Madeira, J. G. C., Morais, V. D., Correa, R. F., ... Gonçalves, R. C. P. (2003). Effect of gamma irradiation on the inactivation of aflatoxin B1 and fungal flora in peanut. Braz. J. Microbiol., 34, 138-140. http://dx.doi.org/10.1590/S1517-83822003000500047

Queirol, M. A. P.,Neto, J. T., Arthur, V.,Wiendl, F. M., \& Villavicencio, A. H. (2002). Gamma radiation, cold and four different wrappings to preserve ginger rhizomes, Zingiber officinallis Roscoe. Rad. Phys. Chem., 63, 341-343. http://dx.doi.org/10.1016/S0969-806X(01)00673-9

Report on Carcinogens (Twelfth Edition) (2011). U.S. Department of Health and Human Services Public Health Service National Toxicology Program.

Sabato, S. F., da Silva, J. M., da Cruz, J. N., Salmieri, S., Rela, P. R., \& Lacroix, M. (2009). Study of physical -chemical and sensorial properties of irradiated Tommy Atkins mangoes (Mangifera indica L.) in an international consignment. Food Control, 20(3), 284-288. http://dx.doi.org/10.1016/j.foodcont.2008.05.005

Sánchez-Bel, P., Egea, I., Romojaro, F., \& Martìnez-Madrid, C. (2008). Sensorial and chemical quality of electron beam irradiated almonds (Prunus amygdalus). LWT - Food Sci. Technol., 41, 442-449. http://dx.doi.org/10.1016/j.lwt.2007.03.015

UNEP. (1992). Fourth meeting of the parties to the Montreal Protocol on substances that deplete the ozone layer. United Nations Environment Programme, Copenhagen.

Villa, P., \& Markaki, P. (2009). Aflatoxin $\mathrm{B}_{1}$ and ochratoxin A in breakfast cereals from athens market: Occurrence and risk assessment. Food Control, 20, 455-461. http://dx.doi.org/10.1016/j.foodcont.2008.07.012

Waje, C. K., Jun, S. Y., Lee, Y. X., Kim, B. N., Han, D. H., Jo, C., \& Kwonet, J. H. (2009). Microbial quality assessment and pathogen inactivation by electron beam and gamma irradiation of commercial seed sprouts. Food Control, 20(3), 200-204. http://dx.doi.org/10.1016/j.foodcont.2008.04.005

WHO. (1999). High-Doses Irradiation: Wholesomeness of Food Irradiated with Doses above $10 \mathrm{kGy}$. Technical Report Series. World Health Organization.

Yu, J., Payne, G. A., Campbell, B. C., Guo, B., Cleveland, T. E., \& Robens, J. F. (2008). Mycotoxin production and prevention of aflatoxin contamination in food and feed. Boca Raton: CRC Press.

\section{Copyrights}

Copyright for this article is retained by the author(s), with first publication rights granted to the journal.

This is an open-access article distributed under the terms and conditions of the Creative Commons Attribution license (http://creativecommons.org/licenses/by/3.0/). 